\title{
3D Imaging of Dead Sea Area Using Weighted Multipath Summation: A Case Study
}

\author{
Shemer Keydar, ${ }^{1}$ Benjamin Medvedev, ${ }^{1,2}$ Abdallah Al-Zoubi, \\ Michael Ezersky, ${ }^{1}$ and Emad Akkawi ${ }^{3}$ \\ ${ }^{1}$ Project Department, The Geophysical Institute of Israel, Lod 71100, Israel \\ ${ }^{2}$ Schlumberger, Via dell'Unione Europea, 4 San Donato Milanese, Milan, Italy \\ ${ }^{3}$ Engineering Faculty, Al-Balqa' Applied University, Salt 19117, Jordan \\ Correspondence should be addressed to Shemer Keydar; shemer@gii.co.il
}

Received 4 November 2012; Revised 27 January 2013; Accepted 28 January 2013

Academic Editor: Umberta Tinivella

Copyright (C) 2013 Shemer Keydar et al. This is an open access article distributed under the Creative Commons Attribution License, which permits unrestricted use, distribution, and reproduction in any medium, provided the original work is properly cited.

\begin{abstract}
The formation of sinkholes along the Dead Sea is caused by the rapid decline of the Dead Sea level, as a possible result of human extensive activity. According to one of the geological models, the sinkholes in several sites are clustered along a narrow coastal strip developing along lineaments representing faults in NNW direction. In order to understand the relationship between a developing sinkhole and its tectonic environment, a high-resolution (HR) three-dimensional (3D) seismic reflection survey was carried out at the western shoreline of the Dead Sea. A recently developed 3D imaging approach was applied to this 3D dataset. Imaging of subsurface is performed by a spatial summation of seismic waves along time surfaces using recently proposed multipath summation with proper weights. The multipath summation is performed by stacking the target waves along all possible time surfaces having a common apex at the given point. This approach does not require any explicit information on parameters since the involved multipath summation is performed for all possible parameters values within a wide specified range. The results from processed $3 \mathrm{D}$ time volume show subhorizontal coherent reflectors at approximate depth of 50-80 $\mathrm{m}$ which incline on closer location to the exposed sinkhole and suggest a possible linkage between revealed fault and the sinkholes.
\end{abstract}

\section{Introduction}

During the last thirty years, hundreds of sinkholes have appeared along the Dead Sea (DS) shoreline in both Israel and Jordan (Figure 1) [1-3]. The process began in the southern part of the DS coast and slowly spread northward along the western coast. The eastern coast which is usually steeper has been less affected at the flat-lying region close to the Lisan Peninsula. The sinkholes have already caused considerable damage to infrastructure, and there is obvious potential for further collapses beneath main highways and other infrastructure.

In order to understand the relationship between a developing sinkhole and its tectonic environment, a numerous number of high resolution seismic reflection surveys were carried out using common midpoint (CMP) technique [3, $5,6]$. The high-resolution seismic reflection method is intended for the study faults and conduits in the shallow subsurface (down to $100-200 \mathrm{~m}$ deep), which could bring the fresh water to the salt layer presumably from below. The conventional processing technique, the so-called common midpoint (CMP) method, essentially consists of a "stack" (summation) of properly corrected traces thus increasing the signal-to-noise ratio. However, in the shallow subsurface, the conventional CMP method causes a loss of information because of the problem of "stretching" of data caused by NMO time correction formula. That is why a new $2 \mathrm{D}$ and $3 \mathrm{D}$ free stretch imaging approach had been applied in the framework of the MERC project M27-050 in order to examine tectonic hypothesis connecting the sinkholes with tectonic faults [7-9]. This approach involves zero-offset common shot point (CSP) stacking and diffraction imaging method [9]. On the basis of those methods in combination with a new weighted multipath summation technique $[10,11]$, a package 


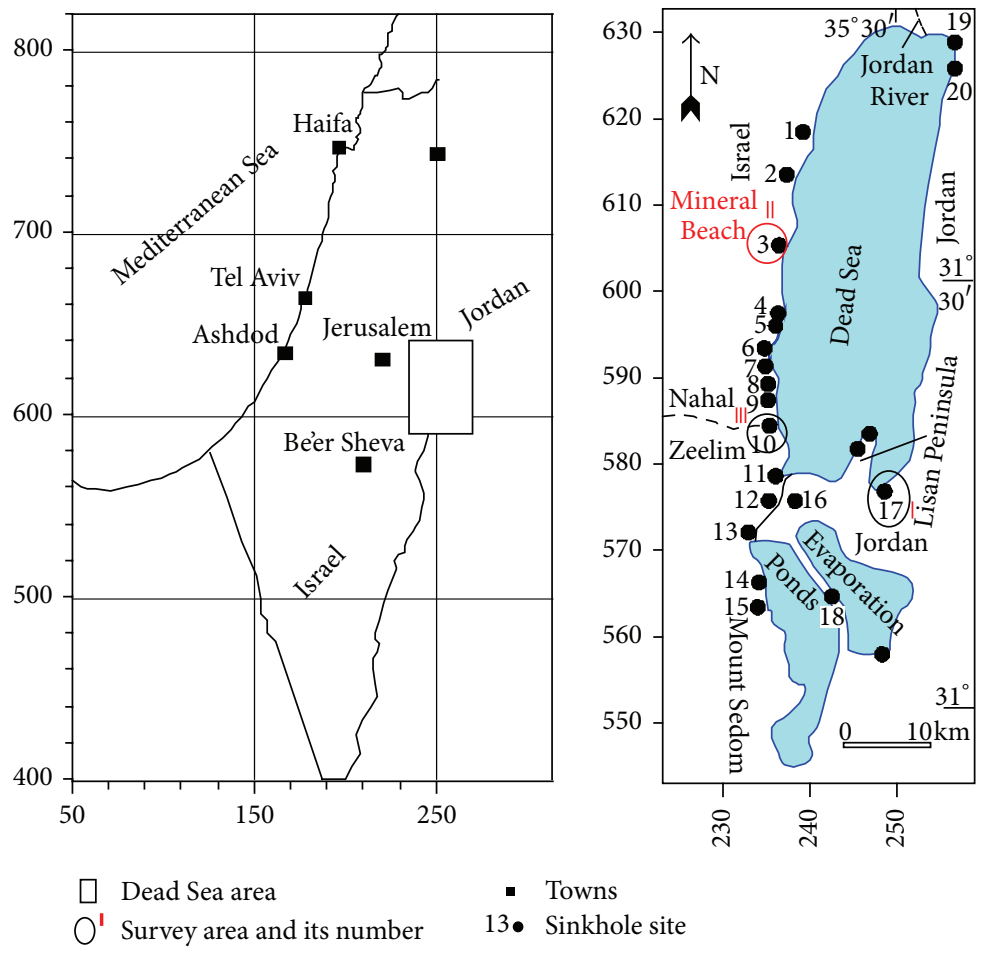

Figure 1: Sinkhole sites along the Dead Sea shore: (1) Palms, (2) Samar Spring, (3) Mineral Beach, (4) Ein Gedi and Nahal Arugot, (5) Yesha, (6) Zeruya, (7) Nahal Hever northern, (8) Nahal Hever southern, (9) Asael, (10) Nahal Zeelim, (11) Mezada, (12) Rahaf, (13) Mor, (14) Ein Boqeq, (15) Newe Zohar, (16) Lisan Peninsula, (17) Ghor Al-Haditha, (18) Dam-2. I-III: sites under investigation. (coordinates are in km, new Israel Mercator grid).

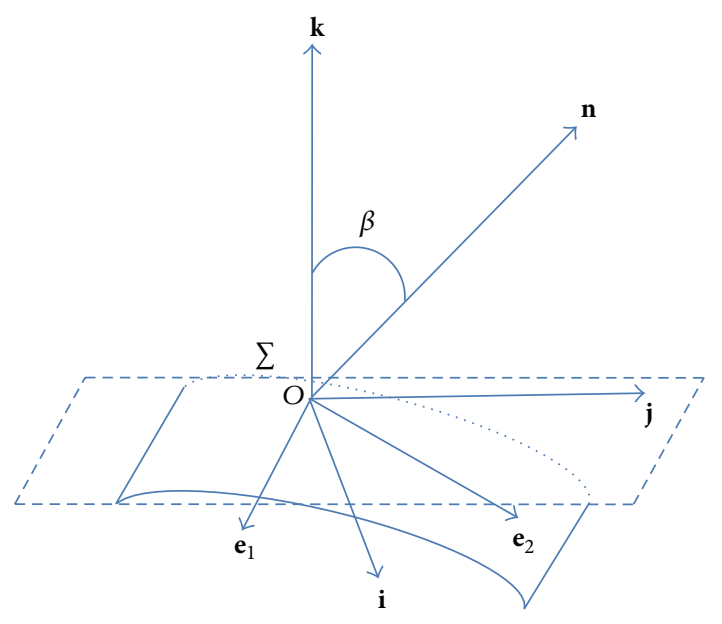

Figure 2: Scheme of wavefront arriving at a Common Shot Point.

of programs was written. The CSP stack and diffraction method are complementary to each other and reveal useful information about the subsurface. The diffraction method serves as a tool for detection of faults and voids, while the CSP stacking contains information about the structure of the subsurface. These methods were applied along the Dead Sea's

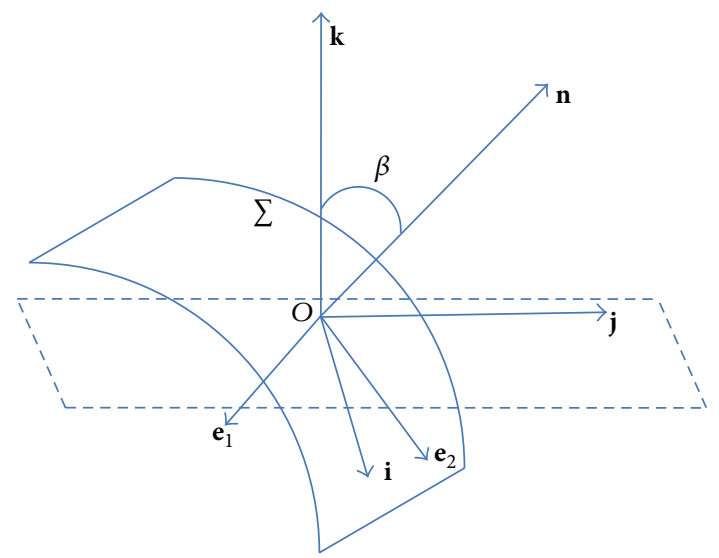

FIGURE 3: The same as Figure 2 in case of one direction is normal to vector $\mathbf{k}$.

shorelines. We have carried out several new seismic surveys along line crossing the sinkhole lineaments and reinterpreted a number of previous reflection sections. The $2 \mathrm{D}$ imaging technique has been presented in [7]. This paper examines the new 3D imaging approach and its application to $3 \mathrm{D}$ data that was acquired at the western shoreline of the Dead Sea. The results of the imaging allow better understanding between 


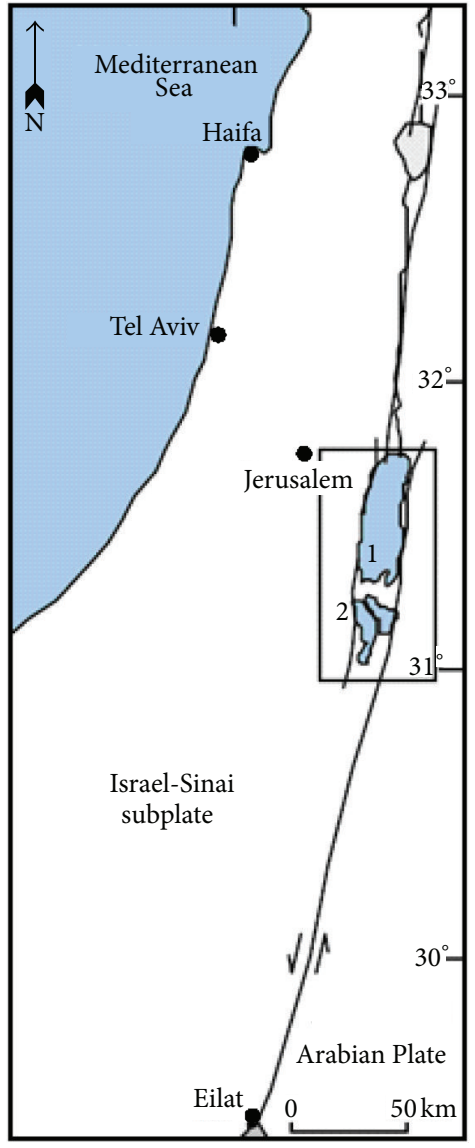

(a)

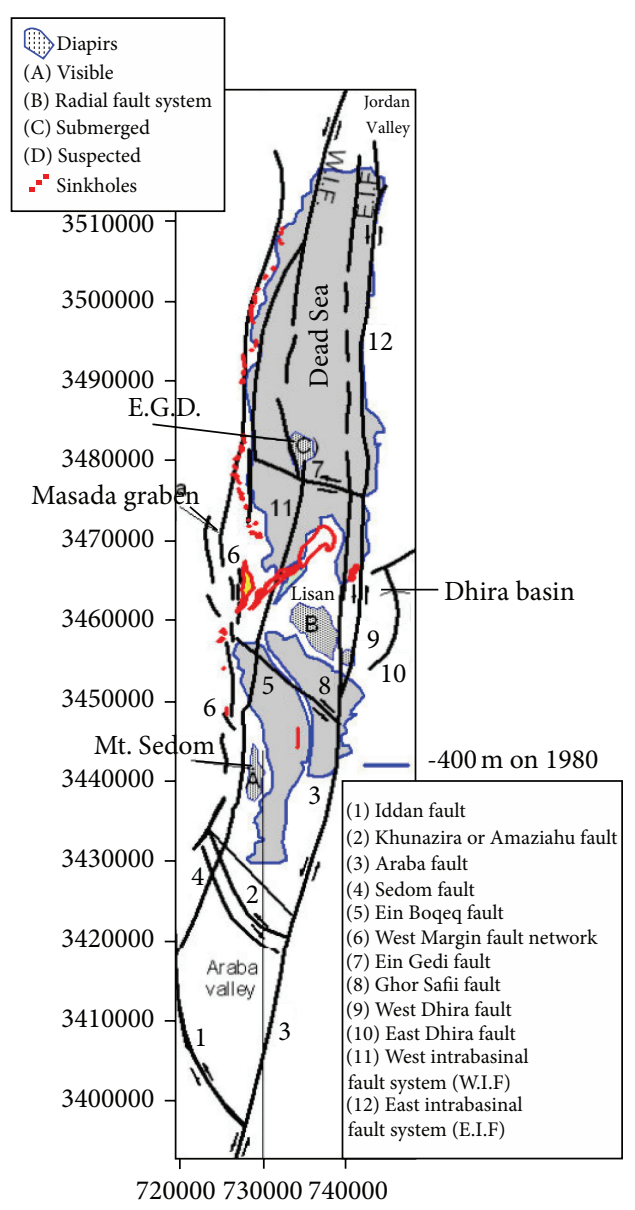

(b)

Figure 4: Dead Sea tectonic setting: (a) Dead Sea transform; (b) faults through the DS area [4].

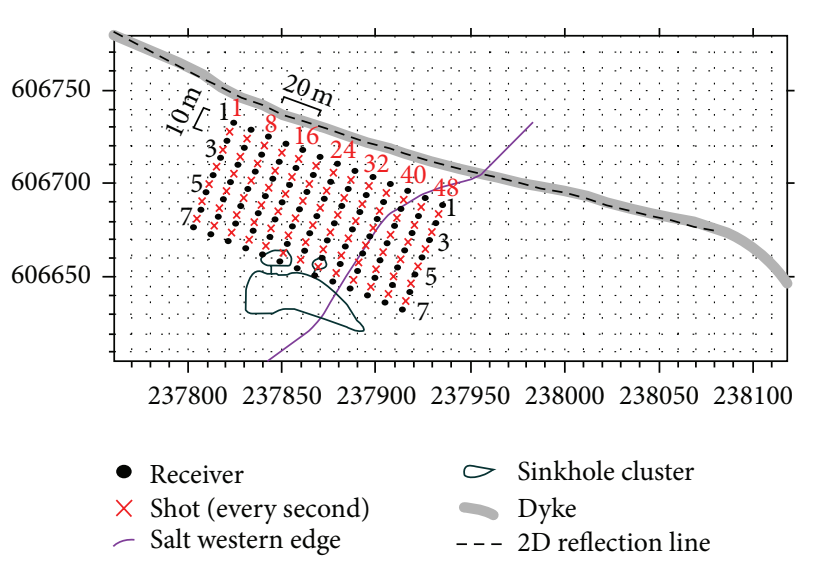

Figure 5: The geometry of 3D seismic survey.

a developing sinkhole and its tectonic environment. We give here a short description of 3D zero-offset stacking and multipath weighted summation. For a more comprehensively discussion of the methods, one can read in the relevant papers.

\section{The 3D Zero Offset Stacking Method}

The basis of the 3D zero-offset stacking method is a new normal moveout (NMO) time correction formula for threedimensional media as function on wavefront parameters [11, 12]. One of these parameters on which the proposed time correction formula is based is the emergence angle $\beta$, defined as the acute angle between the wavefront normal and the normal to the acquisition plane at the CSP. Let us consider a central ray and its associated wavefront arriving at a common shot point (CSP) (Figure 2).

An ellipsoidal wavefront emerges at the CSP location $O$. It has two independent vectors $\mathbf{e}_{1}$ and $\mathbf{e}_{2}$ tangent to the wavefront and the normal $\mathbf{n}$. The emergence angle $\beta$ is the angle between $\mathbf{n}$ and the normal to the acquisition plane, $\mathbf{k}$. Additional fundamental parameters on which the time correction formula is based are the curvatures of the wavefront. It is well known from the differential geometry of surfaces that at each point of the wavefront two principal curvatures can be defined, being the eigenvalues of the $2 \times 2$ matrix of second derivatives. These curvatures are the minimal and maximal curvatures and are related to the mean and Gaussian curvatures. The principal curvatures are associated 


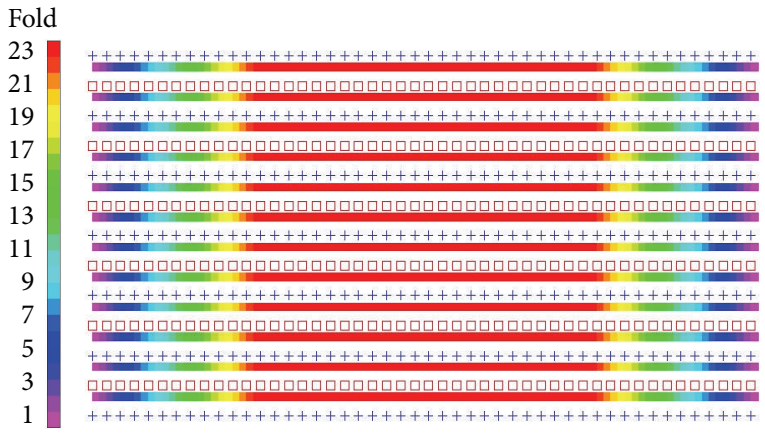

(a)

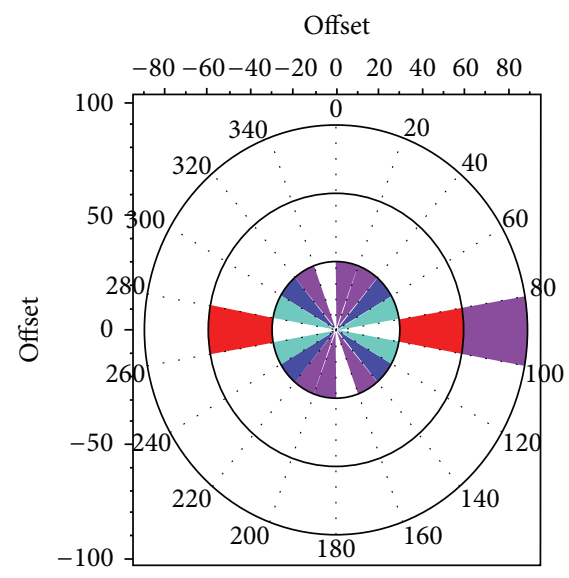

(b)

Figure 6: Fold scheme. (a) The shots locations are marked by "+” and receivers locations are marked by squares, (b) fold as function of azimuth.

to two perpendicular principal directions, which together with the wavefront normal form a rectangular system of axes. The curvature of the wavefront is completely described by the two principal curvatures and the angle the principal directions make with the general coordinate system. This is denoted in Figure 2 as $\mathbf{i}, \mathbf{j}$, and $\mathbf{k}$. The principal curvatures can be expressed in terms of principal radii of curvature, which play an important role in the traveltime correction expressions derived in this paper. Figure 3 illustrates the case where one of the principal directions is normal to $\mathbf{k}$. Based on those principles and eikonal equation only, the following $3 \mathrm{D}$ travel-time correction formula for an arbitrary system of coordinates was obtained:

$$
\begin{aligned}
& t= \frac{1}{V}\left(a_{31} x+a_{32} y\right)+\frac{1}{2 V R_{1}}\left(a_{11} x+a_{12} y\right)^{2} \\
&+\frac{1}{2 V R_{2}}\left(a_{21} x+a_{22} y\right)^{2}+\cdots, \\
& a_{31}= \sin \beta \sin \phi, \quad a_{32}=-\sin \beta \cos \phi, \\
& a_{11}=\cos \phi, \quad a_{12}=\sin \phi, \\
& a_{21}=-\cos \beta \sin \phi, \quad a_{22}=\cos \beta \cos \phi,
\end{aligned}
$$

where $\beta$ is the emergence angle of the wavefront at point $O$, $\phi$ azimuth angle, defined as the angle between the axis $O \widetilde{X}$ and the principal direction of the wavefront at point $O, \tilde{x}$ and $\tilde{y}$ are the offsets along the axis $O \widetilde{X}$ and $O \tilde{Y}$. For a given source receiver, gather the moveout equations that express the moveout correction with respect to a zero-offset trace by five parameters measured at the central point. The parameters are principal radii of the wavefront $R_{1}, R_{2}$, the azimuth angle $\phi$, the emergence angle $\beta$, and the reference velocity $V$.

In the following, we give a short description of the weighted multipath summation.

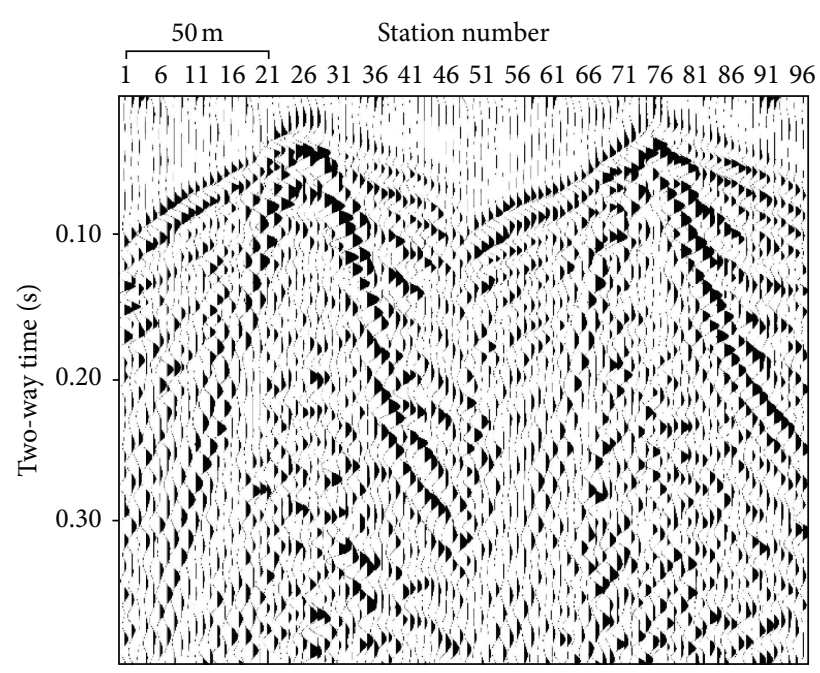

FIGURE 7: Typical common shot gathering including 96 channels.

\section{Multipath Summation}

The summation of $3 \mathrm{D}$ stacking is performed along time surfaces defined by (1). The summation can be implemented using either of the two approaches. In the first conventional approach, the target waves are stacked along the time surfaces defined by wavefront parameters and velocity. These optimal parameters usually are estimated using optimization problem which consists of finding parameters which maximize some correlation functional. We use an alternative, more formal recently proposed multipath summation with a proper weighting [10, 13-15]. The weighted multipath summation allows us to replace the complex optimization problem of estimating the optimal parameters, by summation along all possible surfaces that are created from small variations 


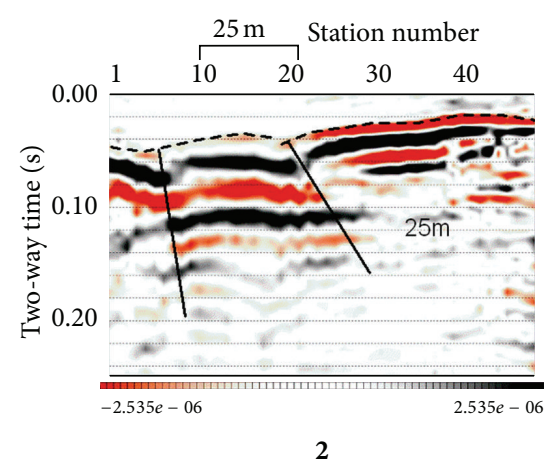

Number of reflection sections

-.- Reflector surface

$\backslash \backslash$ Faults
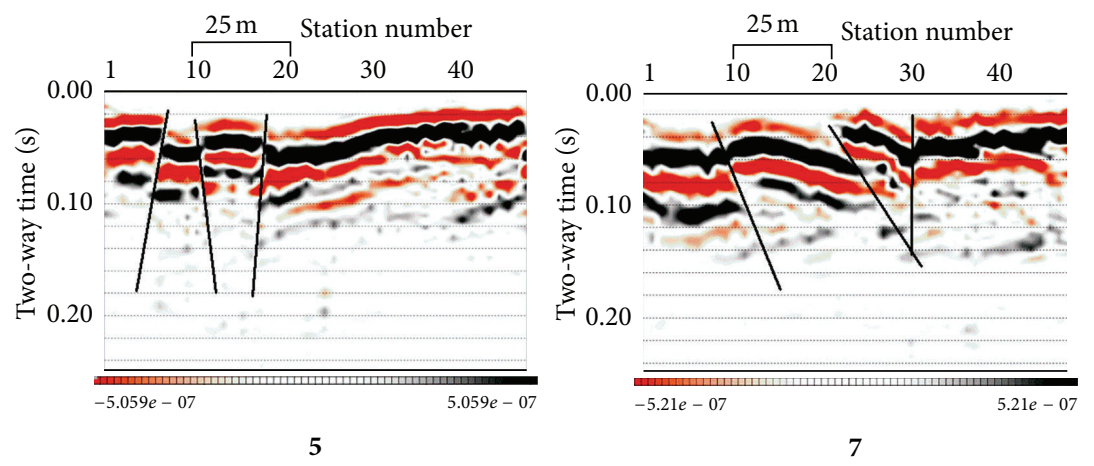

7

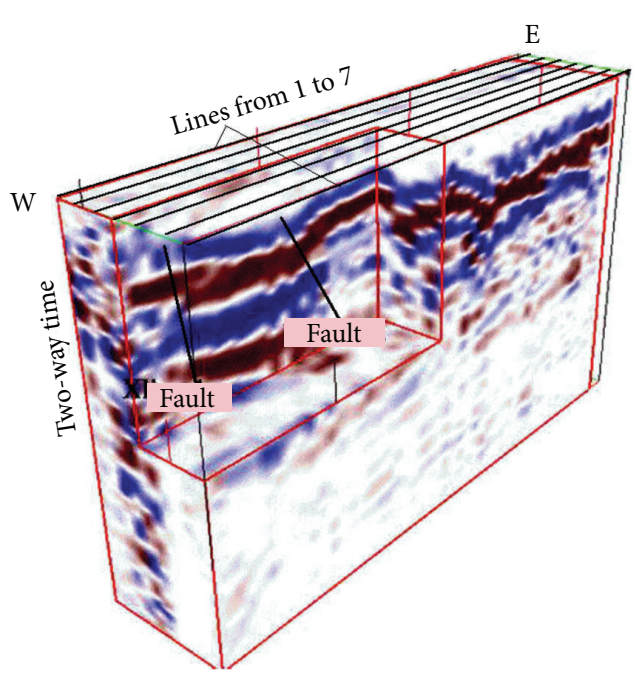

(b) (a)

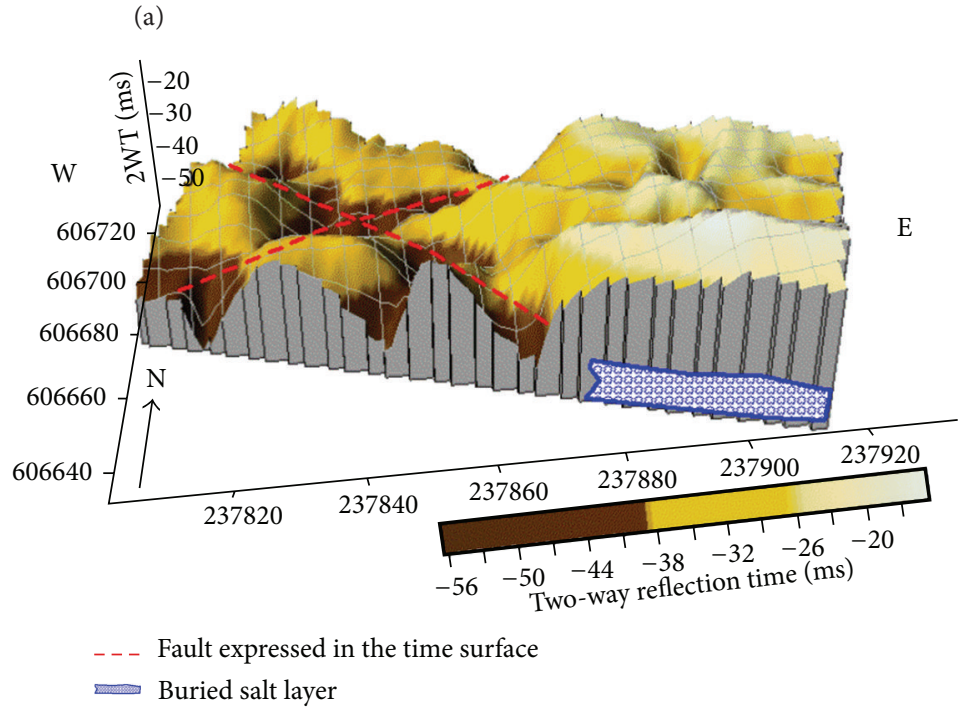

(c)

Figure 8: Typical two-way time sections (a) constructed from 3D time cube obtained using 3D imaging approach (b); two-way time map of reflector in the $3 \mathrm{D}$ presentation (c).

of those parameters. The weighted multipath summation (WMPS) can be described by the following expressions:

$$
\begin{gathered}
I_{\mathrm{WMPS}}=\frac{\sum_{P} I_{P} W\left(I_{P}\right)}{\sum_{P} W\left(I_{P}\right)}, \\
I_{P}=\sum_{P} \sum_{S} \sum_{R} U_{S R}\left(T_{S R}(P)\right),
\end{gathered}
$$

where $W\left(I_{P}\right)=\exp \left(\lambda I_{P}\right)$ is an "optimal" weighting function and $\lambda$ is an undimensional large number. $I_{P}$ is the image obtained for fixed parameters $P$, namely, for radii of curvatures azimuth and emergence angles. $U_{S R}\left(T_{S R}\right)$ is a seismic trace for a given source-receiver pair. $T_{S R}$ is travel time from shot $S$ to receiver $R$. The summation (2) with the proper weight $W\left(I_{P}\right)$ is performed for all possible parameter values within a specified range. The image defined by $I_{P}$ means that for every point to be imaged, seismic amplitudes are stacked together along all possible time surfaces defined by (1). The constructive and destructive interference of the amplitudes contributed by each time surface produces an image close to that obtained by stacking with the "correct" parameter [16].

\section{Case Study}

4.1. Dead Sea Area-Brief Tectonic Setting. Dead Sea (DS) is a pull apart basin or strike-slip one undergone to NWSE compression and NE-SW tensile stress (Figure 4(a)). DS consists of two basins: the northern one (deeper) (denoted by 1 in Figure 4(a)) and the southern one (shallower) (denoted by 2 in Figure 4(a)). And it is extended in approximately N-S direction.

Numerous faults have been detected through DS area (Figure 4(b)) and have mainly extended in the same direction 
$[4,17,18]$. The Dead Sea is located nowadays at elevation of $-426 \mathrm{~m}$ below the sea level (b.s.l).

4.2. Study Site. Mineral beach study site (Figure 1) is located between the Dead Sea shoreline at the east and route number 90 (the main road along the western DS shore) at the west. The area is characterized by N-S normal faults [6]. Around Mineral Beach, sinkholes develop in both mudflat (southern boreholes Mn-2, Mn-5) and alluvial fan (northern borehole Mn-4) areas. Boreholes show that salt layer at the northern part of the area is located at $10 \mathrm{~m}$ deeper ( $-434 \mathrm{~m}$ elevation) than that at the southern one $(-424 \mathrm{~m})$. At the northern part of the area, salt is overlain by sandy-gravel sediments, whereas the southern part is composed of DS mud (clay) overlaying the salt.

The field acquisition covers $120 \mathrm{~m}$ by $60 \mathrm{~m}$ and consists of seven receiver lines in a $10 \mathrm{~m}$ interval between them. Shooting was carried out using six shot lines (288 shots in total) and each shot includes 96 channels in $2.5 \mathrm{~m}$ interval between them. The distance between shot lines is $10 \mathrm{~m}$ (Figure 5).

We used truck mounted accelerated weight (Digipulse) as an energy source and single $10 \mathrm{~Hz}$ geophone per station. In order to image the new developing fault in details, the survey was designed with a full azimuth cover for offsets less than $30 \mathrm{~m}$ (Figure 6).

The data was recorded using $0.5 \mathrm{msec}$ sample rate and $0.5 \mathrm{sec}$ record length. Typical common shot gathers are seen on Figure 7.

The data was processed using the new 3D stacking algorithm. The range of variation of parameters in (2) was as follows: radii of curvature from 3 to 600 meter, emergence angle from -5 to +5 degree, and velocity from $300 \mathrm{~m} / \mathrm{s}$ to $1000 \mathrm{~m} / \mathrm{s}$. The value of $\lambda$ was 900 . The results from processed $3 \mathrm{D}$ imaging are presented in Figure 8(a) as a time sections along reflection lines and in Figure $8(\mathrm{~b})$ as a $3 \mathrm{D}$ cube time section.

A time map of the first reflector is presented in Figure $8(\mathrm{c})$. On all the figures, are clearly seen subhorizontal coherent reflectors at approximate depth of 50-80 m, which incline on closer location to the exposed sinkhole. In addition, faults are seen on all sections (Figure 8(a) sections denoted by 2,5 , and 7 ). These faults are clearly seen on reflector presented in Figure 8(c). The results are consistent with the results that were obtained from a previous $2 \mathrm{D}$ study [3] at the same site. This work provides the first 3D HR imaging on the edge of a sinkhole and nearby fault. The results of the seismic interpretation of 3D image suggest a possible linkage between revealed fault sinkholes and field observation.

\section{Conclusions}

In order to understand the relationship between a developing sinkhole and its tectonic environment, a high-resolution (HR) three-dimensional (3D) seismic reflection survey was carried out at the western shoreline of the Dead Sea. The 3D image of the subsurface was obtained by the use of a recently developed 3D imaging approach. The core of this approach is a new 3D NMO time correction surface formula. Imaging of subsurface is performed by a spatial summation of seismic waves along these time surfaces using recently proposed multipath summation with proper weights. The multipath summation is performed by stacking the target waves along all possible time surfaces having a common apex at the given point. This approach does not require any explicit information on parameters since the involved multipath summation is performed for all possible parameters values within a wide specified range. The results from processed 3D time volume show subhorizontal coherent reflectors at approximate depth of 50-80 m which incline on closer location to the exposed sinkhole and suggest a possible linkage between revealed fault and the sinkholes.

\section{Acknowledgments}

This study has been performed within the framework of MERC project M27-050 fund sponsored by the USAID. Thanks are due to the support of the Israel Ministry of Infrastructure. The authors are also grateful to the Geophysical Institute of Israel for permission to publish this paper.

\section{References}

[1] Y. Arkin and A. Gilat, "Dead Sea sinkholes: an ever-developing hazard," Environmental Geology, vol. 39, no. 7, pp. 711-722, 2000.

[2] A. Frumkin and E. Raz, "Collapse and subsidence associated with salt karstification along the Dead Sea," Carbonates and Evaporites, vol. 16, no. 2, pp. 117-130, 2001.

[3] Y. Yechieli, M. Abelson, A. Bein, O. Crouvi, and V. Shtivelman, "Sinkhole "swarms" along the Dead Sea cost: reflection of disturbance of lake and adjacent groundwater systems," Bulletin of the Geological Society of America, vol. 118, no. 9-10, pp. 10751087, 2006.

[4] Z. Ben-Avraham, "Geophysical framework of the Dead Sea: structure and Tectonics," in The Dead Sea: the Lake and Its Setting, T. M. Niemi, Z. Ben-Avraham, and J. Gat, Eds., pp. 2235, Oxford University Press, Oxford, UK, 1997.

[5] M. Abelson, G. Baer, V. Shtivelman et al., "Collapse-sinkholes and radar interferometry reveal neotectonics concealed within the Dead Sea basin," Geophysical Research Letters, vol. 30, no. 10, pp. 52-1, 2003.

[6] M. Abelson, Y. Yechieli, O. Crouvi et al., "Evolution of the Dead Sea sinkholes," Special Paper of the Geological Society of America, no. 401, pp. 241-253, 2006.

[7] S. Keydar, B. Medvedev, M. Ezerky, and L. Sobolevsky, "Imaging shallow subsurface of Dead Sea area by Common Shot Point stacking and diffraction method using weighted multipath summation," Journal of Civil Engineering and Science, vol. 1, no. 2, pp. 75-79, 2012.

[8] S. Keydar, L. Bodet, C. Camerlynck et al., "A new approach for shallow subsurface imaging and its application to the Dead Sea sinkhole problem," in Proceedings of the 73rd EAGE Conference and Exhibition, pp. 1-4, Vienna, Austria, April 2011.

[9] S. Keydar, B. Medvedev, A. Al-Zoubi, and M. Ezersky, "Another look of imaging of shallow subsurface: real examples from the Dead Sea sinkhole development areas," in EGU General Assembly, vol. 14 of Geophysical Research Abstracts, vol. 14, p. 1432, Vienna, Austria, April 2012. 
[10] S. Keydar, "Homeomorphic imaging using path integrals," in Proceedings of the 66th EAGE Conference \& Exhibition, pp. 710, Paris, France, June 2004.

[11] S. Keydar and M. Mikenberg, "Prestack time migration using the Kirchhoff sum along a new approximation of the reflection travel time curve," in Proceedings of the 72nd European Association of Geoscientists and Engineers Conference and Exhibition (EUROPEC '10), pp. 4916-4920, Barcelona, Spain, June 2010.

[12] S. Keydar and M. Mikenberg, "A new time correction formula in three-dimensional media as a function of wavefront attributes," Journal of Seismic Exploration, vol. 17, no. 4, pp. 349-369, 2008.

[13] S. Keydar and V. Shtivelman, "Imaging zero-offset sections using multipath summation," First Break, vol. 23, pp. 21-24, 2005.

[14] E. Landa, S. Fomel, and T. J. Moser, "Path-integral seismic imaging," Geophysical Prospecting, vol. 54, no. 5, pp. 491-503, 2006.

[15] J. Schleicher and J. C. Costa, "Migration velocity analysis by double path-integral migration," Geophysics, vol. 74, no. 6, pp. WCA225-WCA231, 2009.

[16] V. Shtivelman, S. Keydar, and M. Mikenberg, "Imaging nearsurface inhomogeneities using weighted multipath summation," Near Surface Geophysics, vol. 7, no. 3, pp. 171-177, 2009.

[17] A. Al-Zoubi and U. S. Ten Brink, "Salt diapirs in the Dead Sea basin and their relationship to Quaternary extensional tectonics," Marine and Petroleum Geology, vol. 18, no. 7, pp. 779797, 2001.

[18] A. Frumkin, M. Ezersky, A. Al-Zoubi, E. Akkawi, and A.-R. Abueladas, "The Dead Sea hazard: geophysical assessment of salt dissolution and collapse," Geomorphology, vol. 134, pp. 102117, 2011. 

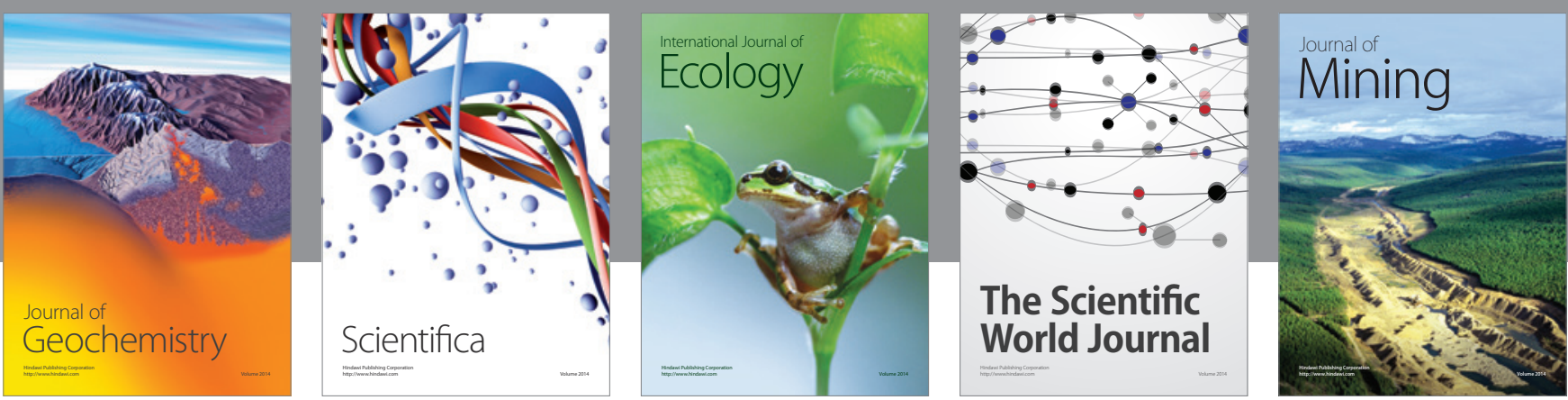

The Scientific World Journal
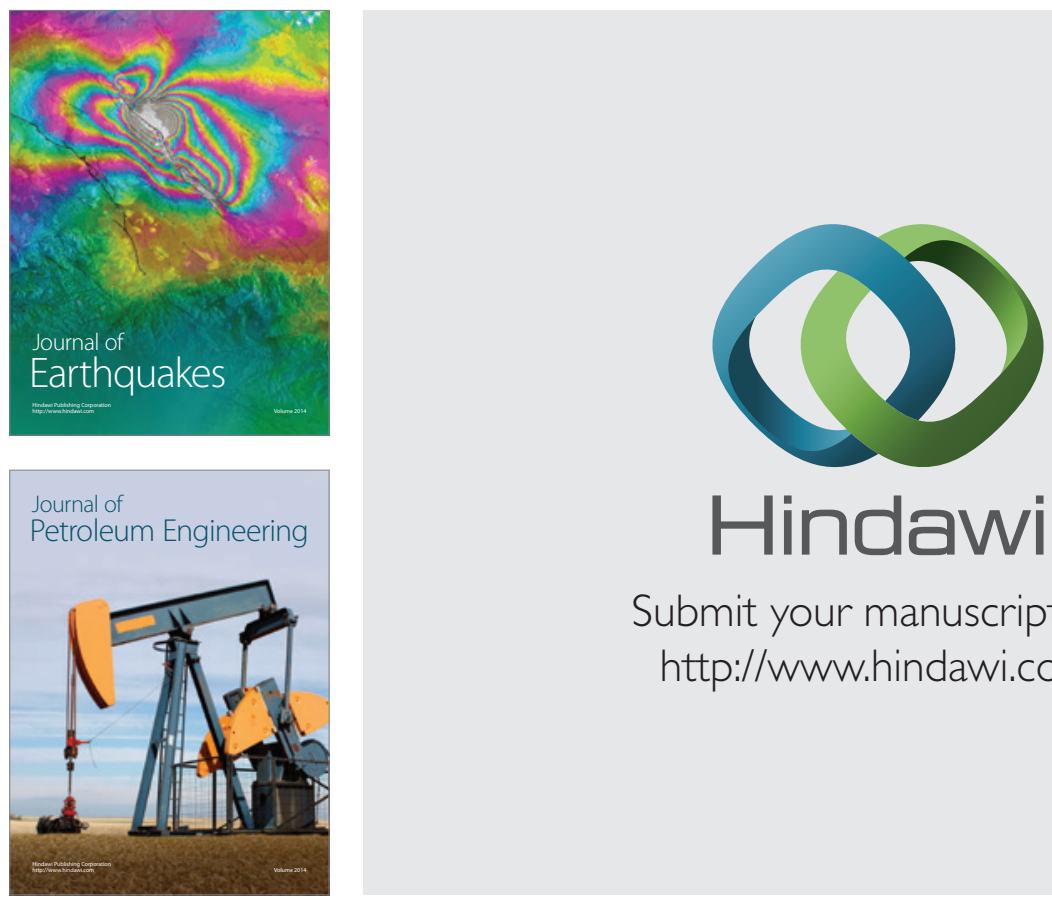

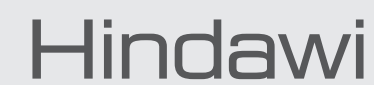

Submit your manuscripts at

http://www.hindawi.com
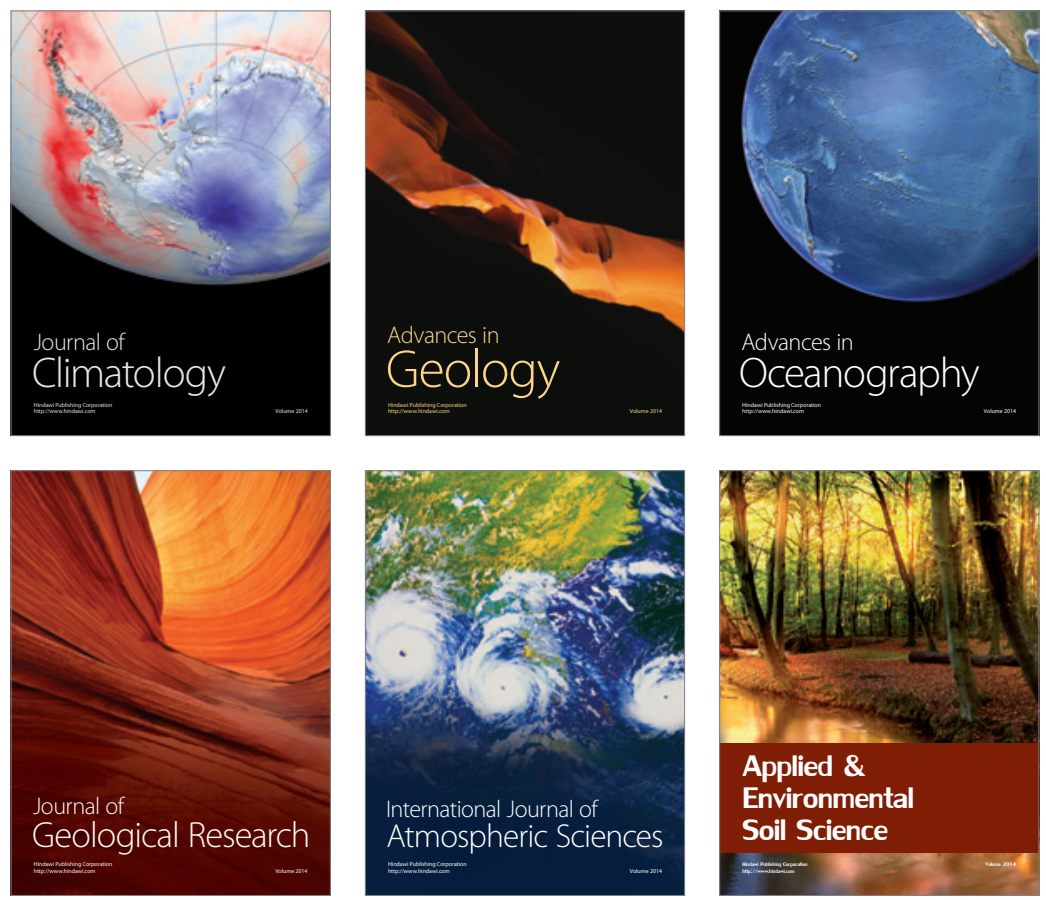
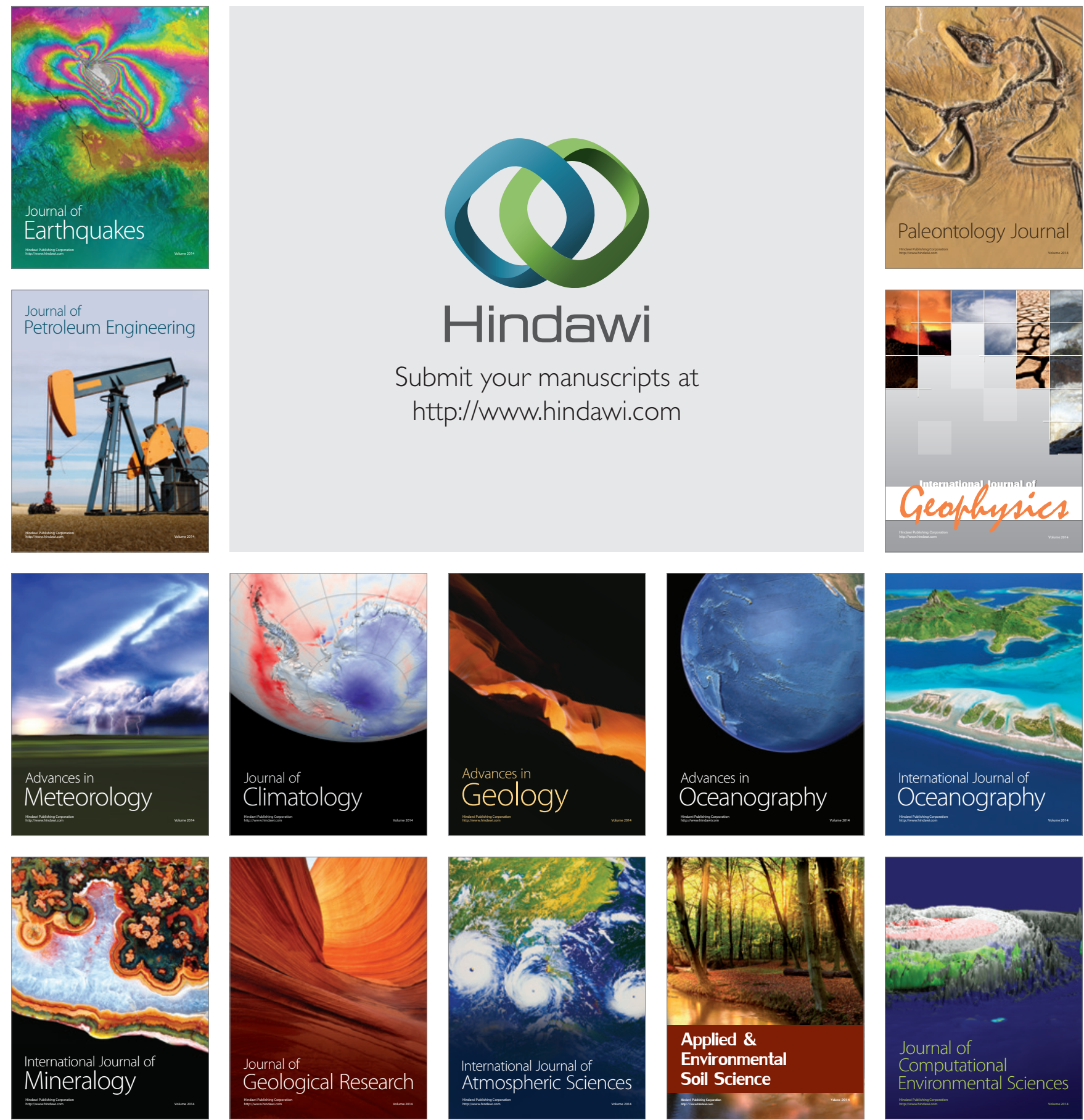